\title{
ASSESSMENT OF MATERNAL AND PERINATAL OUTCOME IN PREGNANCY BEYOND 40 WEEKS OF GESTATION
}

Neeta Sharanabasappa Harwal1, Mahananda Shivarudrappa Melkundi ${ }^{2}$

1 Professor, Department of Obstetrics and Gynaecology, Mahadevappa Rampure Medical College.

${ }^{2}$ Associate Professor, Department of Obstetrics and Gynaecology, Mahadevappa Rampure Medical College.

ABSTRACT

\section{BACKGROUND}

To be expelled timeously from the uterus is almost as important as to be nourished perfectly in it. To be born too late is likely to be disastrous. ${ }^{1}$ Perhaps no clinical problems in Obstetrics create so much emotional response from both the patients and her physicians as does prolonged gestation. ${ }^{2}$ Wrigley in 1958 said, there can be no more an exact time for gestation than an exact height or an exact weight for everyone. ${ }^{3}$ Considering the anxiety of patients and obstetrician and a tendency to induce beyond expected date of delivery, this topic is taken to study the outcome of pregnancy which has crossed the expected date of delivery.

\section{MATERIALS AND METHODS}

A prospective study of 100 cases who crossed the expected date of delivery was conducted during the year 2012-2014 in Basaveshwar and Sangameshwar Teaching and General Hospital attached to M.R. Medical College, Gulbarga.

Inclusion Criteria- With single intrauterine pregnancy with cephalic presentation, previous regular menstrual cycle, no history of using hormonal contraceptive methods three months prior to conception, confirmation of gestational age and expected date of delivery by first trimester or early second trimester scanning.

\section{RESULTS}

$88 \%$ of women went into labour spontaneously and $12 \%$ had to be induced. Of the 88 women who went into spontaneous labour, 54 delivered vaginally and 34 underwent LSCS. Of the 12 who were induced 10 delivered vaginally and 2 underwent LSCS. Foetal distress was the leading (75\%) indication for caesarean section in both primigravida and multigravida. Non-progress of labour, CPD and deep transverse arrest contributed for rest 25\%. In this study, 77\% of babies had birth weight between $2.5-3.5 \mathrm{~kg}$. In this study, an Apgar score at $1^{\text {st }}$ minute of $>7$ was observed in $79 \%$ of newborns. And $87 \%$ of newborns had an Apgar score $>7$ at $5^{\text {th }}$ minute. Admission to NICU and perinatal mortality was highest in babies born to mother with gestational age $\geq 42$ weeks $(27.77 \%$ and $11.11 \%$ respectively).

\section{CONCLUSION}

Though the correct choice of management remains controversial, according to the present study it seems reasonable to induce labour at 41 weeks of gestation as perinatal mortality and morbidity is significantly more after 41 weeks of gestation in our setup.

\section{KEYWORDS}

LSCS, Postdatism, Foetal Distress, CPD.

HOW TO CITE THIS ARTICLE: Harwal NS, Melkundi MS. Assessment of maternal and perinatal outcome in pregnancy beyond 40 weeks of gestation. J. Evolution Med. Dent. Sci. 2017;6(19):1546-1551, DOI: 10.14260/Jemds/2017/339

\section{BACKGROUND}

To be expelled timeously from the uterus is almost as important as to be nourished perfectly in it. To be born too late is likely to be disastrous. ${ }^{1}$

Perhaps no clinical problems in obstetrics create so much emotional response from both the patients and her physicians as does prolonged gestation. ${ }^{2}$ Wrigley in 1958 said, there can be no more an exact time for gestation than an exact height or an exact weight for everyone. ${ }^{3}$

Considering the anxiety of patients and obstetrician and a tendency to induce beyond expected date of delivery, this topic is taken to study the outcome of pregnancy which has crossed the expected date of delivery.

Financial or Other, Competing Interest: None.

Submission 02-01-2017, Peer Review 21-02-2017,

Acceptance 27-02-2017, Published 06-03-2017.

Corresponding Author:

Dr. Neeta Sharanabasappa Harwal,

C/o. Dr. Nagathan Hospital,

Khuba Plot, Gulbarga.

E-mail: neeta.harwal@gmail.com

DOI: $10.14260 /$ jemds $/ 2017 / 339$

\section{(c) $(\mathrm{i)} \odot$}

\section{AIMS AND OBJECTIVES}

To Evaluate-

1. Spontaneous labour rate.

2. Induction rate (Induction is carried out if indicated after assessing maternal and foetal risk factors by antenatal surveillance).

3. Incidence of operative delivery rate (Forceps, ventouse extraction and caesarean section).

4. Duration of labour.

5. Perinatal morbidity (Assessed by low Apgar score, meconium aspiration syndrome and NICU admission) and mortality if any in uncomplicated pregnancies beyond 40 weeks of gestation.

\section{MATERIALS AND METHODS}

A prospective study of 100 cases who crossed the expected date of delivery was conducted during the year 2012-2014 in Basaveshwar and Sangameshwar Teaching and General Hospital attached to M. R. Medical College, Gulbarga.

Patients who fulfilled the following criteria were selected (inclusion criteria). Pregnant women more than 40 weeks of gestation- 
1. With single intrauterine pregnancy with cephalic presentation.

2. Sure of her last menstrual period.

3. Previous regular menstrual cycle.

4. No history of using hormonal contraceptive methods three months prior to conception.

5. Confirmation of gestational age and expected date of delivery by first trimester or early second trimester scanning.

All patients expected date of delivery was calculated as per Naegele's formula.

Only those patients in whom the EDD by LMP and EDD by ultrasonography were coinciding within one week were taken.

Non-stress test was done on admission for all the patients. As per requirement artificial rupture of membrane and augmentation of labour was done with oxytocin drip and smooth muscle relaxation (Drotaverine hydrochloride, Valethamate bromide). Also, as per requirement, routine investigations and ultrasound for foetal weight and foetal parameters (BPP) were done.

Before delivery foetus was assessed for presence of distress, meconium, oligohydramnios. After delivery babies were assessed for evidence of birth asphyxia, hypoxic ischaemic encephalopathy, meconium aspiration syndrome, birth trauma like fractures and number of NICU admissions.

\section{Exclusion}

The patients with unknown dates, irregular menstrual period, malpresentation, previous LSCS maternal complications like gestational hypertension, diabetes, APH and foetal anomalies were excluded.

\section{Management Protocol on Admission}

All those patients who were admitted were assessed on admission and admission test done. The IV line was secured in all patients and hydration was maintained by IV lines or liquids orally.

Proctoclysis enema was given to patients on admission. Patients who were admitted for induction were induced with prostaglandin $\mathrm{E}_{2}$ (Cerviprime) gel intracervically after taking written and informed consent. Patients who were admitted with spontaneous labour were monitored for foetal heart rate, artificial rupture of membranes was done in active phase of labour. Patients with meconium-stained liquor were monitored for foetal heart rate with continuous foetal heart rate monitor.

If required labour was augmented with oxytocin. Also, drotaverine hydrochloride and valethamate bromide injection were given if required. Patients with indication for caesarean section were prepared preoperatively and written and informed consent taken.

The follow-up of the Mother was done on the following lines-

- Induction/Spontaneous labour.

- Mode of delivery.

- Vaginal delivery.

- LSCS.

- Instrumental delivery.

- Duration of labour.

- Colour of the liquor.
The follow-up of babies was done on the following lines -

- Apgar score at $1 \& 5$ minutes.

- Weight.

- Sex.

- Sign of meconium aspiration.

- $\quad$ Sign of birth asphyxia.

- NICU admission \& duration of stay.

- Sign of hypoxic ischemic encephalopathy.

- Perinatal Mortality.

- $\quad$ Evidence of birth trauma.

\section{RESULTS}

\begin{tabular}{|c|c|c|}
\hline Gestational Age & $\begin{array}{c}\text { Number of } \\
\text { Patients }\end{array}$ & Percentage \\
\hline $40+6$ days & 29 & $29 \%$ \\
\hline $41 \mathrm{wks}-41 \mathrm{w}+6$ days & 53 & $53 \%$ \\
\hline$\geq 42 \mathrm{wks}$ & 18 & $18 \%$ \\
\hline Total & $\mathbf{1 0 0}$ & $\mathbf{1 0 0}$ \\
\hline \multicolumn{2}{|c|}{ Table 1. Gestational Age Distribution } \\
\hline
\end{tabular}

Of the total 100 women, $29 \%$ were in $40 \mathrm{wks}-40 \mathrm{wks}+6$ days group, $53 \%$ in 41 wks- $41 w+6$ days group and $18 \%$ in $\geq$ 42 wks group.

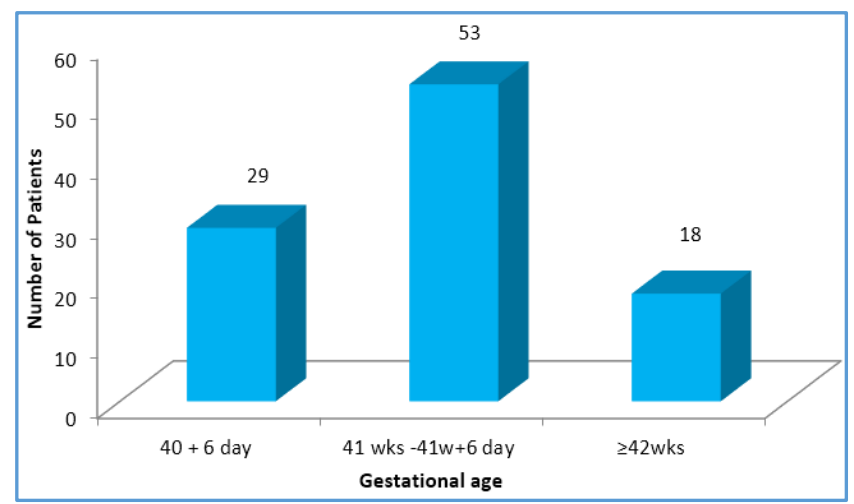

Bar Graph Showing Gestational Age Distribution

\begin{tabular}{|c|c|c|c|}
\hline Gestational Age & Primigravida & Multigravida & Std \\
\hline $40+6$ days & 20 & 9 & 29 \\
\hline 41 wks $-41 w+6$ days & 37 & 16 & 53 \\
\hline$\geq 42$ wks & 13 & 5 & 18 \\
\hline Total & $\mathbf{7 0}$ & $\mathbf{3 0}$ & $\mathbf{1 0 0}$ \\
\hline \multicolumn{2}{|c|}{ Table 2. Distribution According to Parity } \\
\hline
\end{tabular}

In the study population, $70 \%$ were primigravida and $30 \%$ were multigravida.

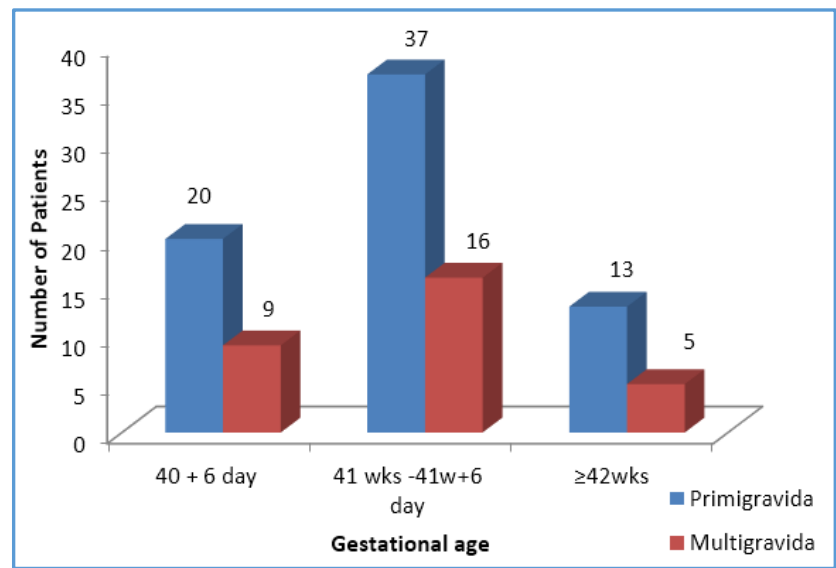

Bar Graph Showing Distribution According to Parity 


\begin{tabular}{|c|c|c|}
\hline Age (Years) & Number of Patients & Percentage \\
\hline$<20$ & 5 & 5 \\
\hline $20-30$ & 92 & 92 \\
\hline$\geq 30$ & 3 & 3 \\
\hline \multicolumn{3}{|c|}{ Table 3. Age Distribution } \\
\hline
\end{tabular}

Most of the women in the study group were between 20 30 years of age.

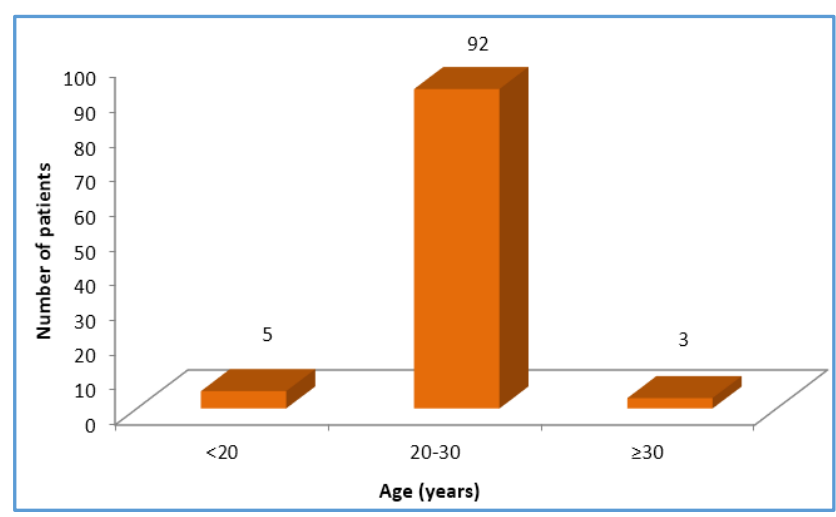

Bar Graph Showing Age Distribution

\begin{tabular}{|c|c|c|}
\hline Mode & Number of patients & Percentage \\
\hline Spontaneous & 88 & 88 \\
\hline Induced & 12 & 12 \\
\hline Total & $\mathbf{1 0 0}$ & $\mathbf{1 0 0}$ \\
\hline \multicolumn{3}{|c|}{ Table 4. Mode of Labour Onset } \\
\hline
\end{tabular}

$88 \%$ of women went into labour spontaneously and $12 \%$ had to be induced.

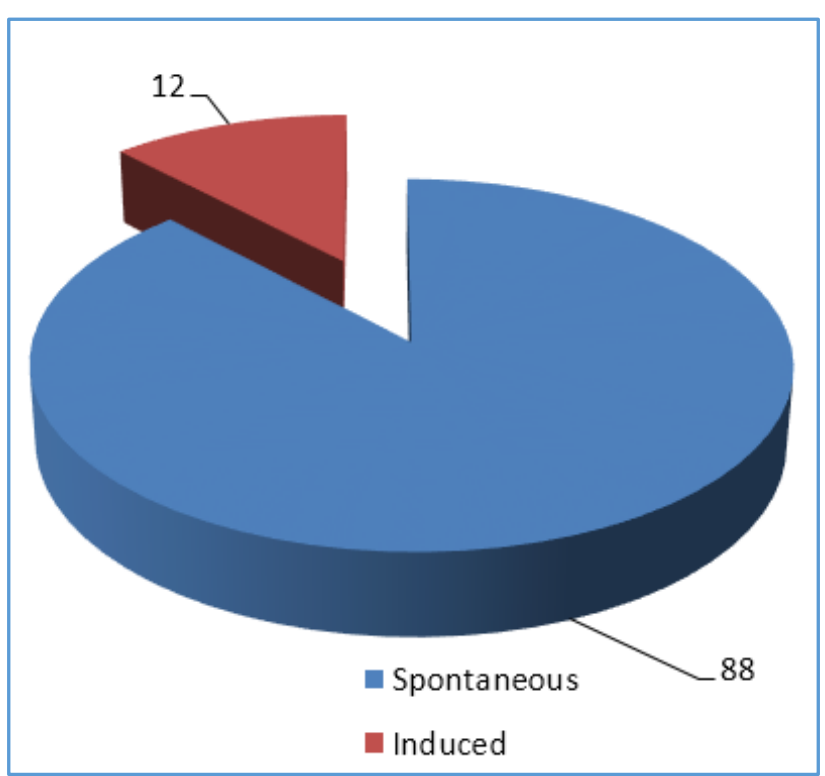

\begin{tabular}{|c|c|c|}
\hline Mode & Number of patients & Percentage \\
\hline Vaginal & 56 & 56 \\
\hline Instrumental & 8 & 8 \\
\hline Caesarean & 36 & 36 \\
\hline \multicolumn{2}{|c|}{ Table 5. Mode of Delivery } \\
\hline
\end{tabular}

$64 \%$ of women delivered vaginally \& $36 \%$ of women underwent LSCS.

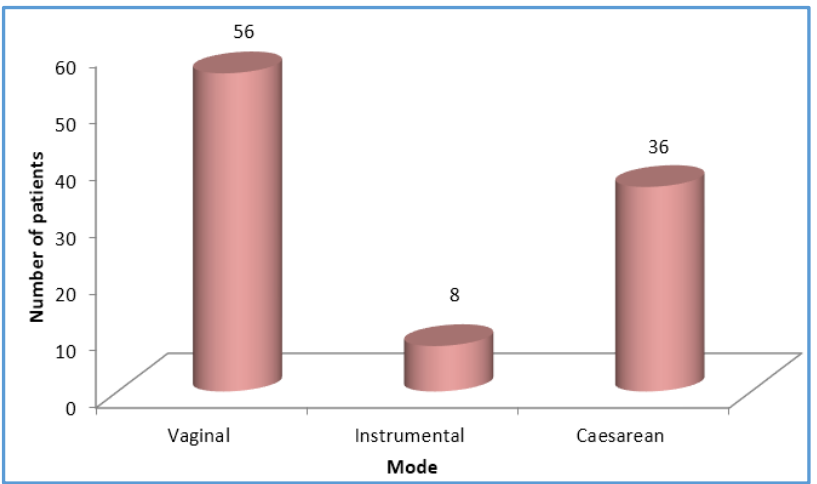

Bar graph Showing Mode of Delivery

\begin{tabular}{|c|c|c|c|c|c|}
\hline Mode & Vaginal & $\mathbf{\%}$ & LSCS & $\mathbf{\%}$ & Total \\
\hline Spontaneous & 54 & 61.3 & 34 & 38.6 & 88 \\
\hline Induced & 10 & 83.3 & 2 & 16.6 & 12 \\
\hline \multicolumn{6}{|c|}{ Table 6. Mode of Labour Onset and Type of Delivery } \\
\hline
\end{tabular}

Of the 88 women who went into spontaneous labour, 54 delivered vaginally and 34 underwent LSCS. Of the 12 who were induced, 10 delivered vaginally and 2 underwent LSCS.

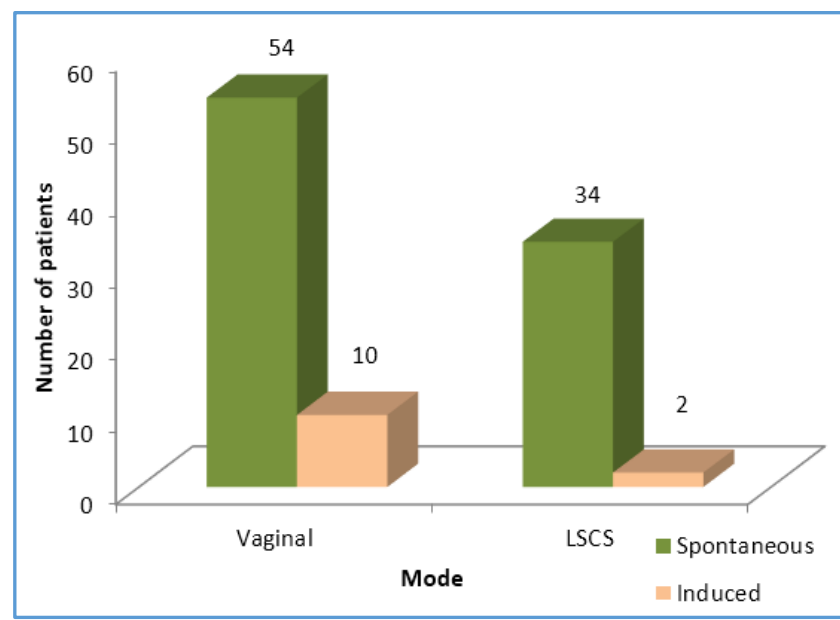

Bar Graph Showing Mode of Labour Onset and Type of Delivery

\begin{tabular}{|c|c|c|c|}
\hline GA & Parity & \begin{tabular}{|c|} 
Number of \\
Patients
\end{tabular} & Percentage \\
\hline \multirow{2}{*}{$\begin{array}{c}\text { 40wks-40wks+6days } \\
(n=29)\end{array}$} & Primi & 17 & 26.5 \\
\hline & Multi & 5 & 7.8 \\
\hline \multirow{2}{*}{$\begin{array}{c}\text { 41wks-41wks+6days } \\
(n=53)\end{array}$} & Primi & 21 & 32.8 \\
\hline & Multi & 11 & 17.1 \\
\hline \multirow{2}{*}{$\begin{array}{l}\geq 42 \text { weeks } \\
\quad(n=18)\end{array}$} & Primi & 5 & 7.8 \\
\hline & Multi & 5 & 7.8 \\
\hline Total & & 64 & \\
\hline \multicolumn{4}{|c|}{ Table 7. Vaginal Delivery Rate } \\
\hline
\end{tabular}

In this study, the vaginal delivery rate in women beyond 40 weeks of gestation is $64 \%$. Of this $67.1 \%$ were primigravida $\& 32.8 \%$ were multigravida. 


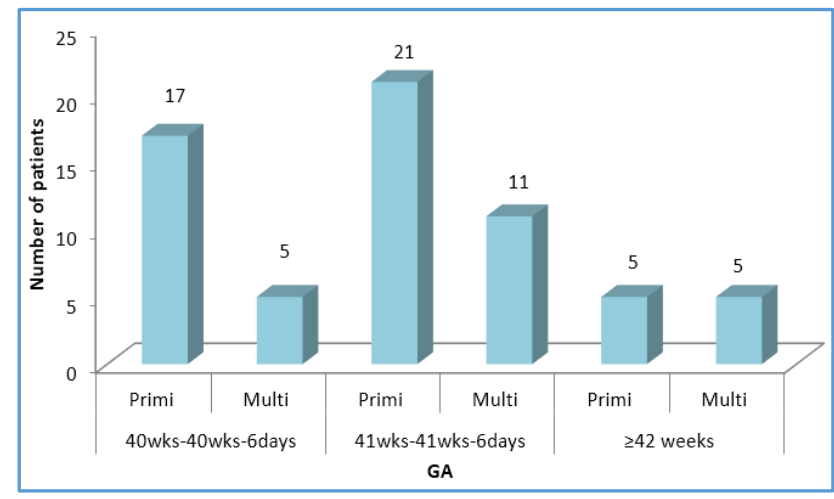

Bar Graph Showing Vaginal Delivery Rate

\begin{tabular}{|c|c|c|c|}
\hline GA & Parity & $\begin{array}{c}\text { No. of } \\
\text { Patient }\end{array}$ & Percentage \\
\hline \multirow{2}{*}{$\begin{array}{c}40 \mathrm{wks}^{-} \\
\text {40wks+6days }(\mathrm{n}=29)\end{array}$} & Primi & 3 & 8.3 \\
\hline & Multi & 2 & 5.5 \\
\hline \multirow{2}{*}{$\begin{array}{c}41 \text { wks- } \\
41 w k s+6 \text { days }(n=53)\end{array}$} & Primi & 13 & 36 \\
\hline & Multi & 7 & 19.4 \\
\hline \multirow{2}{*}{$\geq 42$ weeks $(n=18)$} & Primi & 11 & 30.5 \\
\hline & Multi & 0 & 0 \\
\hline Total & & 36 & \\
\hline \multicolumn{4}{|c|}{ Table 8. Caesarean Section Rate } \\
\hline
\end{tabular}

In this study, caesarean section rate in women beyond 40 weeks of gestation is $36 \%$.

Of this $75 \%$ were primigravida \& $25 \%$ were multigravida.

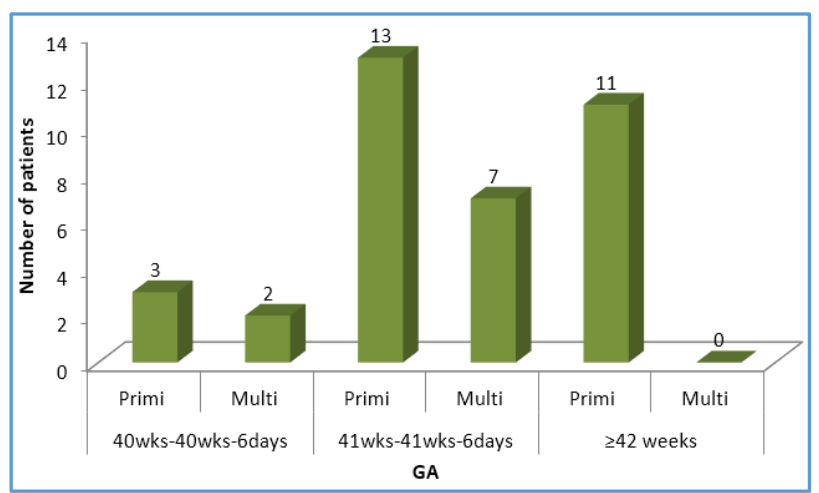

Bar graph Showing Caesarean Section Rate

\begin{tabular}{|c|c|c|c|c|}
\hline Indication & Primi & $\mathbf{\%}$ & Multi & $\mathbf{\%}$ \\
\hline Foetal distress & 21 & 58 & 6 & 16.6 \\
\hline Non progress & 2 & 5.5 & 1 & 2.7 \\
\hline CPD & 4 & 11 & 0 & 0 \\
\hline $\begin{array}{c}\text { Deep transverse } \\
\text { arrest }\end{array}$ & 1 & 2.7 & 1 & 2.7 \\
\hline \multicolumn{6}{|c|}{ Table 9. Indications for Caesarean Section } \\
\hline
\end{tabular}

Foetal distress was the leading (75\%) indication for caesarean section in both primigravida \& multigravida. Nonprogress of labour, CPD and deep transverse arrest contributed for rest $25 \%$.

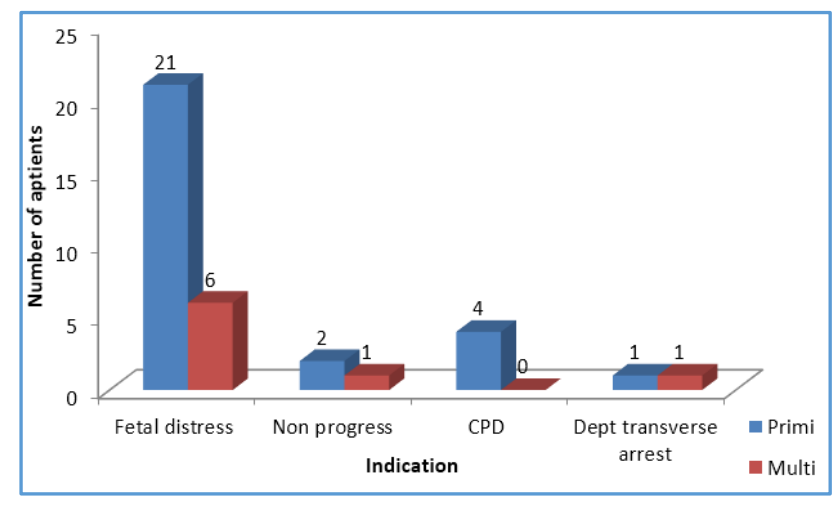

Bar Graph Showing Indication for Caesarean Section

\begin{tabular}{|c|c|c|}
\hline GA & Vacuum & Percentage \\
\hline 40wks-40wks+6days & 5 & 62.5 \\
\hline $41 w k s-41 w+6$ days & 3 & 37.5 \\
\hline$\geq 42 \mathrm{wks}$ & 0 & 0 \\
\hline \multicolumn{3}{|c|}{ Table 10. Vacuum Extraction } \\
\hline
\end{tabular}

In total, $8 \%$ had instrumental delivery.

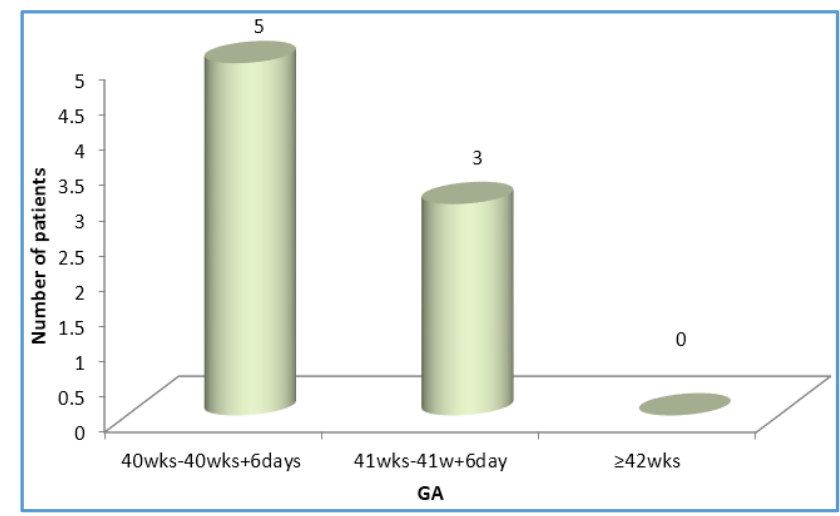

Bar Graph Showing Vacuum Extraction

\begin{tabular}{|c|c|c|}
\hline GA & No. of Patients & $\%$ \\
\hline 40wks-40wks+6days $n=29$ & 4 & 13.7 \\
\hline 41 wks-41w+6days $n=53$ & 20 & 37.7 \\
\hline$\geq 42$ wks $n=18$ & 9 & 50 \\
\hline \multicolumn{3}{|c|}{ Table 11. Incidence of Meconium-stained Liquor } \\
\hline
\end{tabular}

Incidence of meconium-stained liquor was highest in the gestational age group $\geq 42$ Weeks $(50 \%)$.

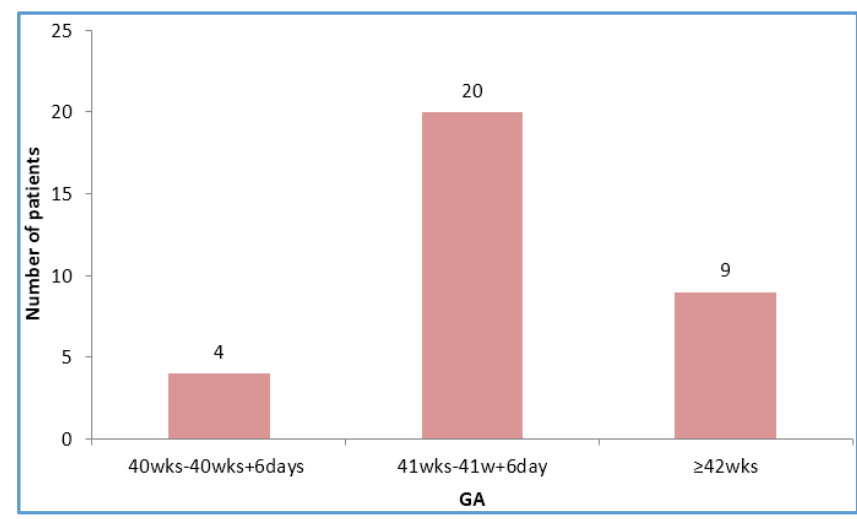

Bar Graph Showing Incidence of Meconium-stained Liquor 


\begin{tabular}{|c|c|c|c|}
\hline Duration & $\begin{array}{c}\text { 40wks-40w+6 } \\
\text { days } \\
(\mathbf{n = 2 2})\end{array}$ & $\begin{array}{c}\mathbf{4 1 w k s -} \\
\mathbf{4 1 w + 6} \text { days } \\
(\mathbf{n = 3 2})\end{array}$ & $\begin{array}{c}\mathbf{2 4 2 w k s} \\
(\mathbf{n = 1 0})\end{array}$ \\
\hline$<6 \mathrm{hrs}$. & 4 & 10 & 3 \\
\hline $7-12 \mathrm{hrs}$. & 3 & 16 & 3 \\
\hline $12-18 \mathrm{hrs}$. & 14 & 6 & 4 \\
\hline$>18 \mathrm{hrs}$. & 1 & 0 & 0 \\
\hline \multicolumn{4}{|c|}{ Table 12. Duration of Labour } \\
\hline
\end{tabular}

There was no undue prolongation in duration of labour in any of the study group.

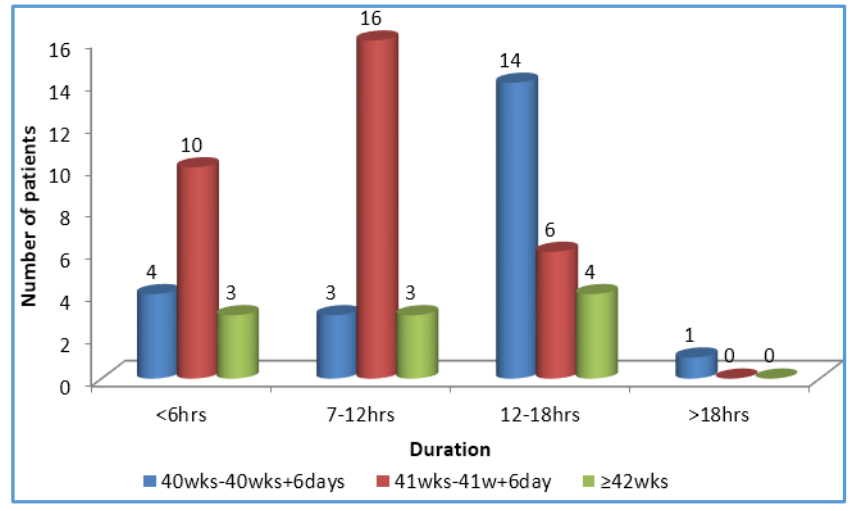

Bar graph Showing Duration of Labour

\begin{tabular}{|c|c|c|}
\hline GA & No. of Patients & $\mathbf{\%}$ \\
\hline 40wks-40wks+6days $(\mathrm{n}=29)$ & 7 & 24.2 \\
\hline 41wks-41w+6days $(\mathrm{n}=53)$ & 18 & 33.9 \\
\hline$\geq 42 \mathrm{wks}(\mathrm{n}=18)$ & 6 & 33.3 \\
\hline \multicolumn{2}{|c|}{ Table 13. Incidence of Oligohydramnios } \\
\hline
\end{tabular}

In total, incidence of oligohydramnios was $31 \%$. Incidence of oligohydramnios increased as the gestational age advanced.

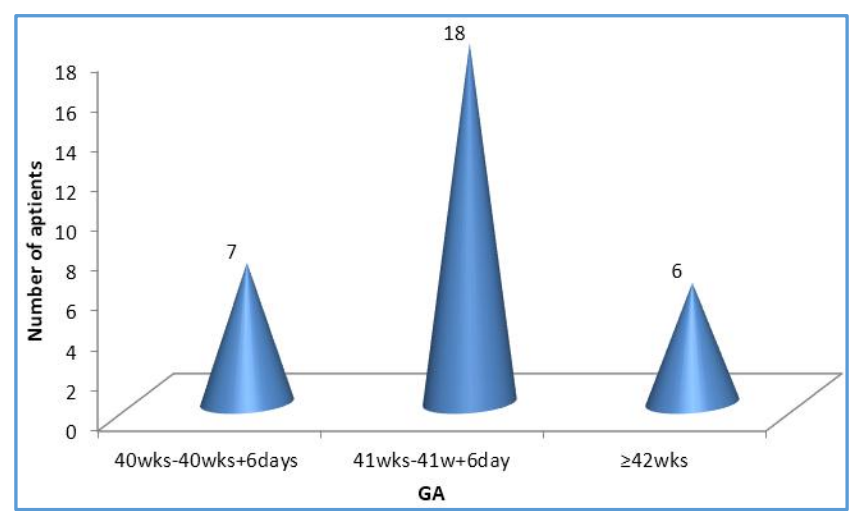

Bar graph Showing Incidence of Oligohydramnios

\begin{tabular}{|c|c|c|c|c|}
\hline $\begin{array}{c}\text { Birth } \\
\text { Weight (Kg) }\end{array}$ & $\begin{array}{c}\mathbf{4 0} \text { wks-40 } \\
\text { wks + 6 days } \\
(\mathrm{n}=\mathbf{2 9})\end{array}$ & $\begin{array}{c}\mathbf{4 1} \text { wks-41 } \\
\text { wks + 6 days } \\
(\mathrm{n}=\mathbf{5 3})\end{array}$ & $\begin{array}{c}\mathbf{4 4 2} \text { wks } \\
(\mathrm{n}=\mathbf{1 8})\end{array}$ & Total \\
\hline$<2.5$ & 3 & 5 & 2 & 10 \\
\hline $2.5-3.5$ & 23 & 41 & 13 & 77 \\
\hline$\geq 3.5$ & 3 & 7 & 3 & 13 \\
\hline \multicolumn{5}{|r|}{ Table 14. Birth Weight and Gestational Age } \\
\hline
\end{tabular}

In this study, 77\% of babies had birth weight between 2.5 -3.5 kgs.

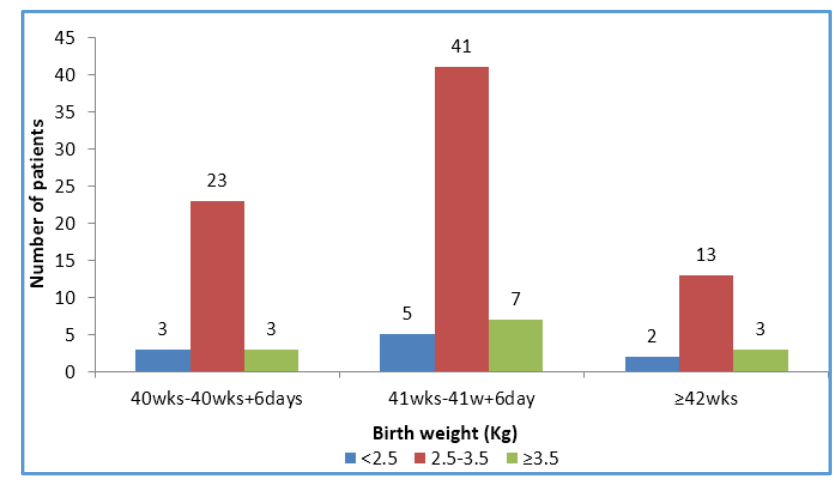

Bar Graph Showing Birth Weight and Gestational Age

\begin{tabular}{|c|c|c|c|c|}
\hline \multicolumn{2}{|c|}{ Apgar score } & $\begin{array}{c}\text { 40wks- } \\
\text { 40wks+6days }\end{array}$ & $\begin{array}{c}\text { 41wks- } \\
\text { 41w+6days }\end{array}$ & 242wks \\
\hline \multirow{4}{*}{1 min. } & $<4$ & 1 & 0 & 1 \\
\cline { 2 - 5 } & $4-7$ & 7 & 7 & 1 \\
\cline { 2 - 5 } & $>7$ & 20 & 44 & 15 \\
\hline \multirow{3}{*}{5 min. } & $<4$ & 0 & 0 & 0 \\
\cline { 2 - 5 } & $4-7$ & 1 & 7 & 1 \\
\cline { 2 - 5 } & $>7$ & 24 & 47 & 16 \\
\hline
\end{tabular}

Table 15. Gestational Age and Neonatal Apgar Score

In this study, an Apgar score at $1^{\text {st }}$ minute of $>7$ was observed in $79 \%$ of newborns. And $87 \%$ of newborns had an Apgar score $>7$ at $5^{\text {th }}$ minute.

\begin{tabular}{|c|c|c|c|}
\hline GA & $\begin{array}{c}\text { 40wks- } \\
\text { 40wks+6days } \\
(\mathbf{n = 2 9 )}\end{array}$ & $\begin{array}{c}\text { 41wks- } \\
\text { 41w+6days } \\
(\mathbf{n = 5 3 )}\end{array}$ & $\begin{array}{c}\text { 242wks } \\
\text { ( } \mathbf{n = 1 8})\end{array}$ \\
\hline $\begin{array}{c}\text { Admission to } \\
\text { NICU }\end{array}$ & 1 & 9 & 5 \\
\hline $\begin{array}{c}\text { Perinatal } \\
\text { mortality }\end{array}$ & 3 & 0 & 2 \\
\hline \multicolumn{3}{|c|}{ Table 16. Gestational Age \& Perinatal } \\
Mortality and Morbidity \\
\hline
\end{tabular}

Admission to NICU and perinatal mortality was highest in babies born to mother with gestational age $\geq 42$ weeks $(27.77$ $\%$ and $11.11 \%$ respectively).

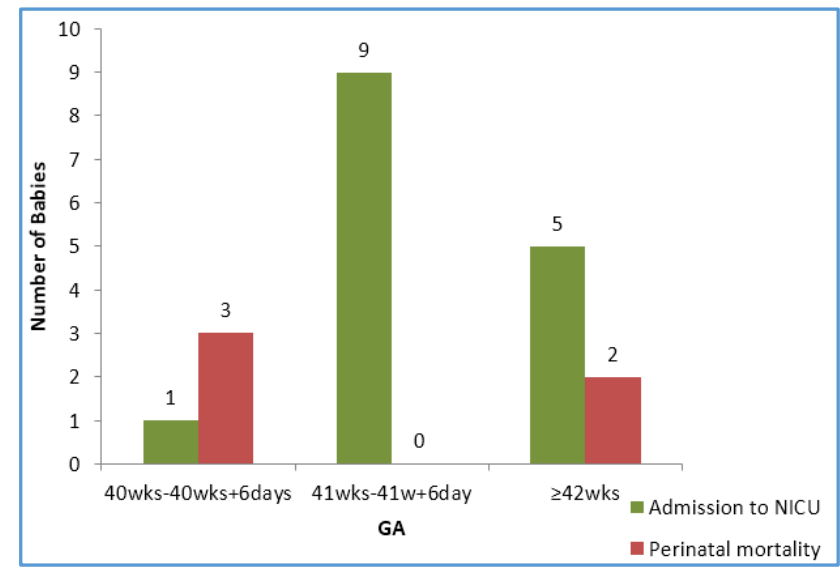

Bar Graph Showing Perinatal Mortality and Morbidity 


\section{DISCUSSION}

The purpose of this study is to assess pregnancy outcomes at 40-41, 41-42 and beyond 42 weeks of gestation.

100 women without confounding variables such as hypertension, diabetes, prior caesarean birth, non-cephalic presentation, foetal malformations or placenta praevia were included in this study done over a period of 18 months.

In Table 1, the study population is distributed according to gestational age. Of the total 100 women, 29 were in 40 weeks' group; 53 in 41 weeks' group and 18 were in $>42$ weeks' group.

Tables 2 and 3 show distribution of the subjects according to parity and age respectively. Most women (92\%) were between 20-30 years of age and 70\% were primigravida. Most of the authors agree that pregnancy beyond 40 weeks is found mainly in primigravida. ${ }^{4}$

Among 100 women, 88 (88\%) went into spontaneous labour and 12 (12\%) were induced. As per Table 6, 54 women had spontaneous vaginal delivery, 10 delivered vaginally after induction and 34 women who went into spontaneous labour had caesarean section and 2 among the induced group underwent caesarean section.

A prospective study was conducted by Prabha Singal et al to evaluate the maternal and foetal outcome in prolonged pregnancy at Ajmer in which labour started spontaneously in $54 \%$ and induction was done in $46 \%$ of the total 150 postdated patients. ${ }^{5}$

According to Tables 6 in our study, vaginal delivery rate in women who went into spontaneous labour was $61.3 \%$ and among induced women it was $83.3 \%$. In the study by Prabha Singal et al vaginal delivery rates in the spontaneous labour group and induced group were $91.4 \%$ and $74 \%$ respectively. According to meta-analysis of randomised controlled trials, a policy of labour induction at 41 weeks of gestation reduces the caesarean delivery rates. ${ }^{6}$

\section{CONCLUSION}

The management of pregnancy beyond 40 weeks remains controversial. The value of routine induction of labour in such pregnancy also remains controversial because of the concern that it may result in an increase in the incidence of caesarean section without any significant improvement in the foetal outcome. In infants admitted to NICU one of the risk factor attributed is postdatism.

So, care of the post-dated foetus should start right from in utero. In this complex clinical condition, we should identify the foetus at risk and to institute an appropriate management following adequate counselling of patient.

Considering the changing attitude of women, the trauma of a caesarean section is much less than mental trauma and its unfortunate consequence of losing a perfectly normal baby or having a neonatal morbidity.

Though the correct choice of management remains controversial, according to the present study it seems reasonable to induce labour at 41 weeks of gestation as perinatal mortality and morbidity is significantly more after 41 weeks of gestation in our setup.

\section{REFERENCES}

[1] Ballantyne JW. The problem of postmature infant. J Obstet Gynecol Br Emp 1902;2(6):521-54.

[2] Miller FC, Lead JA. Intrapartum assessment of the postdate fetus. Am J Obstetrics \& Gynaecol 1981;141(6):516-20.

[3] Misra R. Ian Donald's practical obstetric problems. $7^{\text {th }}$ edn. Wolters Kluwer 2014:432.

[4] Cunningham FG, Kenneth JL, Steven LB, et al. Williams obstetrics. 23 ${ }^{\text {rd }}$ edn. New York (USA): McGraw-Hill 2010:pp 832.

[5] Singal P, Sharma A. Fetomaternal outcome following postdate pregnancy-a prospective study. J Obst Gynecol of India 2001;51(5):89-93.

[6] Sanchez-Ramos L, Olivier F, Delke I, et al. Labor induction versus expectant management for postterm pregnancies: a systematic review with meta analysis. Obstet Gynecol 2003;101(6):1312-8. 